\title{
Ultrastructure of heart muscle in short-term diabetic rats: influence of insulin treatment
}

\author{
A. Reinilä and H. K. Åkerblom \\ Department of Pathology, University of Oulu, Oulu and the Children's Hospital, University of Helsinki, Helsinki, Finland
}

\begin{abstract}
Summary. The ultrastructure of myocardium was examined in short-term diabetic rats. Morphometric analysis showed the volume of myocytic mitochondria, sarcoplasmic reticulum and lipid droplets to be significantly increased compared with those of control animals. Further measurements of mitochondria and sarcoplasmic reticulum indicated that the augmentation of these compartments was accountable by the enlargement of pre-existing mitochondria, which were swollen, and of pre-existing tubules of sarcoplasmic reticulum, the lumen of which was dilated. After insulin treatment the morphological changes were returned to normal which indicates that they were not due to the toxic effect of streptozotocin but were caused by the diabetic state per se. This suggestion is further
\end{abstract}

supported by the finding that experimentally induced metabolic acidosis without diabetes did not cause any morphologically detectable changes in the heart muscle. It is concluded that short-term diabetes in the rat causes mitochondrial swelling, dilatation of sarcoplasmic reticulum and accumulation of lipid in cardiac myocytes, and that these changes are preventable with insulin treatment. We suggest that insulin may have an important role in the maintenance of metabolism in heart muscle.

Key words: Ultrastructure, heart muscle, streptozotocin, shortterm diabetes, insulin treatment.
Several studies in man and experimental animals suggest that diabetes causes a heart disease independent of coronary atherosclerosis [1-4]. Some authors have proposed that the diabetic cardiomyopathy may be due to myocardial microvascular disease $[5,6]$ or to autonomic nervous system disease $[7,8]$, while others have suggested that possible abnormalities of energy utilization pathways exist in diabetic heart muscle [4].

Most experimental studies on diabetic cardiomyopathy have been carried out on long-term diabetic animal models, and only a few investigators have paid attention to the short-term effects of insulin deficiency on the morphology of the heart muscle [9]. The aim of this study was to examine in detail the ultrastructure of heart muscle in short-term diabetic rats, and the influence of insulin treatment on myocardial morphology.

\section{Materials and methods}

\section{Animals}

Male Sprague-Dawley rats weighing $180-200 \mathrm{~g}$ were used. Twelve rats were made diabetic with streptozotocin (Upjohn, lot $1613 \mathrm{E}, \mathrm{MCM} 2$, $3 \mathrm{~g} / 100 \mathrm{ml}$ ), freshly prepared in $0.1 \mathrm{~mol} / 1$ citrate buffer $(\mathrm{pH} 4.5)$ and injected intraperitoneally in a dose of $100 \mathrm{mg} / \mathrm{kg}$ body weight. Six control rats received an equal volume of buffer intraperitoneally. In addition, six normal rats were rendered acidotic by substituting $1.5 \%$ $\mathrm{NH}_{4} \mathrm{Cl}$ (wt/vol) for their drinking water for 7 days [10]. The animals were fed normal laboratory chow ad libitum, containing $53 \%$ carbohydrate, $20.9 \%$ protein, $4.5 \%$ fat, $3.9 \%$ fibre together with the usual vitamins and minerals (Hankkija, Turku, Finland). Six diabetic rats were killed 7 days after the induction of diabetes. The six control animals and the six non-diabetic $\mathrm{NH}_{4} \mathrm{Cl}$-treated rats were killed at the same time.

\section{Insulin treatment and balance of diabetes}

The remaining six diabetic animals were treated with insulin, treatment being initiated 4 days after the induction of diabetes. Daily lente insulin (Novo, 4-10 units) was given subcutaneously. The dose of insulin was adjusted according to plasma glucose concentration, and the amount of glycosuria (Clinitest) and ketonuria (Ketostix) were controlled daily at $08.00 \mathrm{~h}$. These animals were killed 3 days after the initiation of insulin treatment, i.e. 7 days after the induction of diabetes.

\section{Analysis of blood specimens}

Blood was drawn from the retro-orbital venous plexus of non-fasting rats through a capillary tube under light ether anaesthesia and collected into ice-cold tubes. Capillary tubes for $\mathrm{pH}$ determination were filled immediately and kept at $4^{\circ} \mathrm{C}$ until analysis for $\mathrm{pH}$ was carried 

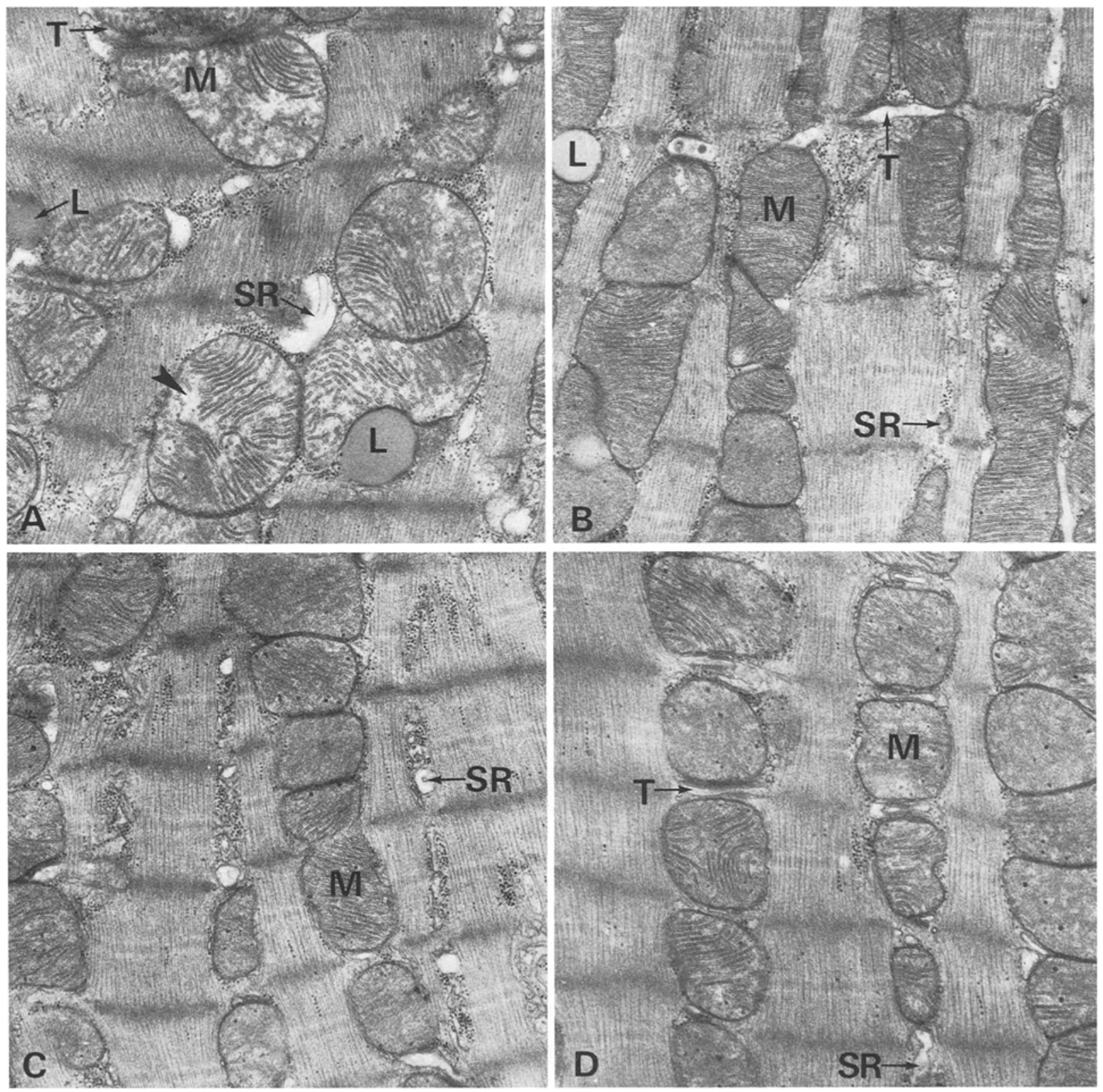

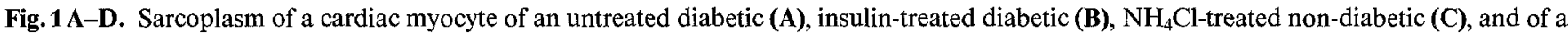
control rat (D). Note patchy swelling of the matrix space (at arrowhead) and a rounded form of mitochondria (M), and dilatation of sarcoplasmic reticulum (SR) in the untreated diabetic animal (A). $\mathrm{L}=$ lipid droplets, $\mathrm{T}=\mathrm{T}$-tubule. $\mathrm{A}-\mathbf{D}(\times 20,000)$

out with a capillary electrode within half an hour. Blood samples for the analysis of other substances were collected into tubes of ice-cold EDTA to a final concentration of $21.7 \mu \mathrm{mol} / 1$, and capillary tubes were filled for the measurement of blood haematocrit. The blood samples were kept at $4^{\circ} \mathrm{C}$ for $2 \mathrm{~h}$ after which the plasma was separated and used for the analyses of plasma glucose, insulin, non-esterified fatty acids (NEFA), triglycerides, acetoacetate and $\beta$-hydroxybutyrate.

Plasma glucose was determined by an ultraviolet hexokinase method (Boehringer, Mannheim, FRG) using an Auto-Analyzer II (Technicon, Tarrytown, NY, USA), acetoacetate and $\beta$-hydroxybutyrate were measured by a kinetic method (Boehringer) using a System Olli 3000 Photometer 334 (Kone, Espoo, Finland), plasma triglycerides by a kinetic ultraviolet method (Boehringer) using the same instrument, and plasma NEFA by a colorimetric method (Boehringer) using a Hitachi 101 Spectrophotometer (Tokyo, Japan). Plasma insulin was measured by a solid phase ${ }^{125}$ I-radioimmunoassay (Coat-A-
Count, Diagnostic Products Corporation, Los Angeles, CA, USA). The detection limit of this assay is $2 \mathrm{mU} / 1$. The assay is standardized in terms of WHO's first International Reference Preparation 66/304.

\section{Handling of tissue specimens}

The animals were killed at 7 days immediately after taking the blood samples. The body cavity was opened under light ether anaesthesia, the heart was quickly removed and put into ice-cold $0.9 \%$ saline for $15 \mathrm{~s}$ to stop the beating. Thereafter, the heart was put onto cold dental wax, cold $2.5 \%$ glutaraldehyde was dripped on the tissue, the lateral wall of left ventricle was cut off and divided into cubes of $1 \mathrm{~mm} \times 1 \mathrm{~mm}$ with a razor blade. The tissue pieces were placed into vials containing $2.5 \%$ glutaraldehyde in $0.1 \mathrm{~mol} / 1$ sodium cacodylate solution ( $\mathrm{pH} \mathrm{7.4)}$ where they were immersed for $30 \mathrm{~min}$. The time from opening the chest cavity until placing the tissue specimens into 
fixative was $40-50 \mathrm{~s}$. After immersion fixation the specimens were washed in $0.1 \mathrm{~mol} / 1$ sodium cacodylate buffer ( $\mathrm{pH} 7.4$ ) for $5 \mathrm{~min}$, and post-fixed in $2 \% \mathrm{OsO}_{4}$ in $0.1 \mathrm{~mol} / 1$ sodium cacodylate solution ( $\mathrm{pH}$ 7.4) for $2 \mathrm{~h}$. The tissues were then rapidly dehydrated in graded acetone [11] and embedded in Lx-112 Resin (Ladd Research Industries, Burlington, Vermont, USA). All steps until embedding were carried out at $4^{\circ} \mathrm{C}$.

Semi-thin sections $(1 \mu \mathrm{m}$ thick) were cut with a glass knife from the blocks chosen at random and examined by phase contrast microscopy (Leitz, Wetzlar, FRG) until five blocks with myofibres oriented longitudinally were obtained for each animal. The thin sections were cut with a diamond knife from the same five blocks, stained with uranyl acetate and lead citrate and examined in an electron microscope (JEM-100 Cx II, JEM-100 B, Japan Electron Optics Laboratory, Tokyo, Japan).

\section{Morphometry}

A uniform sampling of 25 micrographs of each heart was utilized for the morphometric analyses. Five random fields from each of the five tissue blocks were micrographed at 1,000 and printed at a final magnification of 3,000 . The square array of 140 sampling points [12] was placed on each micrograph, and the number of points falling over specific structures was counted as a measure of the volume fraction of myocytes, myocyte nuclei and sarcoplasm, and the interstitial tissue including capillaries and cells other than myocytes [13]. Thus a total of 3,500 points was examined in each heart.

For the measurement of the volume fractions of sarcoplasmic organelles of cardiac myocytes, five random fields were micrographed from the same five blocks at 10,000 , and printed at a final magnification of 30,000 . The square array of 345 sampling points which covered a tissue area of $38 \mu \mathrm{m}^{2}$, i. e. $0.11 \mu \mathrm{m}^{2}$ per point, was used for determining the volume fraction of myofibrils, mitochondria, sarcoplasmic reticulum, matrix, T-system, lipid droplets and other structures [13]. The sarcoplasmic matrix contained amorphous regions, glycogen granules, free ribosomes and polyribosomes. The small amount of rough endoplasmic reticulum was combined with the Golgi apparatus and other organelles in the category of other sarcoplasmic structures. Perinuclear and plasmalemmal regions as well as the intercalated discs were not micrographed.

A total of 8,625 points representing $950 \mu \mathrm{m}^{2}$ of myocytic sarcoplasm was examined in each heart. In addition, the number of the profiles of mitochondria and of the tubules of sarcoplasmic reticulum was counted in the micrographs [12]. The mean surface area of the mitochondria and of the tubules of sarcoplasmic reticulum was calculated by dividing the total area of mitochondria and sarcoplasmic reticulum by the number of the profiles of mitochondria and sarcoplasmic reticulum, respectively [12]. Average dimensions of mitochondrial profiles were also determined by measuring the longitudinal axis (parallel to myofibrils) and the transverse axis (perpendicular to myofibrils) of 100 randomly chosen mitochondria in each heart.

\section{Statistical analyses}

The results are expressed as mean \pm SEM, the statistical differences between mean values being calculated using Student's t-test. The regression analyses were performed by the method of least squares.

\section{Results}

\section{Untreated diabetic rats}

The 12 rats injected with streptozotocin $(100 \mathrm{mg} / \mathrm{kg}$ body weight) lost $8-17 \%$ of their body weight and had high concentrations of plasma glucose $(20.1 \pm 2.2$ mmol/1), NEFA $(0.88 \pm 0.15 \mathrm{mmol} / 1)$, triglycerides $(5.21 \pm 1.20 \mathrm{mmol} / \mathrm{l})$, acetoacetate $(0.45 \pm 0.11 \mathrm{mmol} / \mathrm{l})$ and $\beta$-hydroxybutyrate $(5.79 \pm 0.95 \mathrm{mmol} / \mathrm{l}) 4$ days af ter the induction of diabetes. Their average water consumption increased from 25 to $85 \mathrm{ml}$ a day, and they developed $3-5 \%$ glycosuria and slight $(+)$ to severe $(+++)$ ketonuria. These rats $(n=6)$ lost further weight within the next 3 days, the weight loss being $11-20 \%$ at 7 days, their plasma concentrations of glucose, lipids and ketone bodies were increased, and they were strongly hypoinsulinaemic (Table 1). The blood haematocrit was $0.41 \pm 0.02$ at 7 days before killing the animals. They were acidotic, the mean blood $\mathrm{pH}$ being 7.22 (range 7.17-7.27).

\section{Insulin-treated diabetic animals}

The animals treated with insulin gained weight, two out of six reaching their initial weight at 3 days. Ketonuria was eliminated on day 2 , and aglycosuria was reached on day 3 from the initiation of insulin treatment. Plasma concentrations of glucose, NEFA, triglycerides, acetoacetate and $\beta$-hydroxybutyrate were also restored to the normal range within 3 days (Table 1 ).

\section{Non-diabetic $\mathrm{NH}_{4} \mathrm{Cl}$-treated and control rats}

The six non-diabetic rats rendered acidotic with $\mathrm{NH}_{4} \mathrm{Cl}$ lost $1-2 \%$ of their body weight within 7 days, and their plasma concentrations of glucose, insulin, NEFA, triglycerides, acetoacetate and $\beta$-hydroxybutyrate were similar with those of the six control animals (Table 1 ), which gained $5-7 \%$ weight within 7 days. The mean blood $\mathrm{pH}$ of the non-diabetic $\mathrm{NH}_{4} \mathrm{Cl}$-treated animals was 7.25 (range 7.20-7.30) at 7 days, and that of the control animals 7.38 (range 7.36-7.40). The blood haematocrit was similar in $\mathrm{NH}_{4} \mathrm{Cl}$-treated and control animals $(0.37 \pm 0.02$ and $0.38 \pm 0.01$, respectively).

\section{Morphometric analyses}

The volume fraction of myocardial myocytes, myocyte nuclei and sarcoplasm, and interstitial tissue were similar in untreated diabetic, insulin-treated diabetic, nondiabetic $\mathrm{NH}_{4} \mathrm{Cl}$-treated and control animals (Table 2). However, further morphometric measurements showed several changes in the volume fraction of various sarcoplasmic organelles of untreated diabetic animals compared with the other groups. The volume percentage of mitochondria, sarcoplasmic reticulum and lipid droplets was significantly increased in the untreated diabetic group compared with the insulin-treated diabetic, $\mathrm{NH}_{4} \mathrm{Cl}$-treated non-diabetic, and the control group (Table 2). After treatment with insulin for 3 days the volume fractions of these sarcoplasmic structures restored to the normal level (Table 2). No significant differences were found in the volume fraction of matrix components, tubules of T-system and other organelles between the various groups (Table 2). The number of the profiles of mitochondria and sarcoplasmic reticulum of cardiac 
Table 1. Concentrations of plasma glucose, insulin, NEFA, triglycerides, acetoacetate and $\beta$-hydroxybutyrate in untreated diabetic, insulin-treated diabetic, $\mathrm{NH}_{4} \mathrm{Cl}$-treated non-diabetic, and control rats

\begin{tabular}{|c|c|c|c|c|}
\hline Plasma concentrations & $\begin{array}{l}7 \text {-day } \\
\text { untreated diabetic rats } \\
(n=6)\end{array}$ & $\begin{array}{l}\text { Treated diabetic rats } \\
(n=6)\end{array}$ & $\begin{array}{l}\mathrm{NH}_{4} \mathrm{Cl} \text {-treated } \\
\text { non-diabetic rats } \\
(n=6)\end{array}$ & $\begin{array}{l}\text { Control rats } \\
(n=6)\end{array}$ \\
\hline Insulin (mU/1) & $8.8 \pm 1.4$ & & $35.0 \pm 2.9^{\mathrm{d}}$ & $37.3 \pm 2.2^{\mathrm{d}}$ \\
\hline $\mathrm{NEFA}(\mathrm{mmol} / \mathrm{l})$ & $0.93 \pm 0.12$ & $0.42 \pm 0.02^{\mathrm{c}}$ & $0.40 \pm 0.05^{\mathrm{c}}$ & $0.35 \pm 0.04^{\circ}$ \\
\hline Triglycerides (mmol/l) & $5.83 \pm 1.72$ & $0.53 \pm 0.12^{\mathrm{a}}$ & $0.43 \pm 0.04^{a}$ & $0.46 \pm 0.05^{a}$ \\
\hline Acetoacetate $(\mathrm{mmol} / 1)$ & $0.58 \pm 0.10$ & $0.24 \pm 0.03^{b}$ & $0.17 \pm 0.02^{c}$ & $0.15 \pm 0.03^{c}$ \\
\hline
\end{tabular}

Results expressed as mean \pm SEM.

${ }^{\mathrm{a}} p<0.02,{ }^{\mathrm{b}} p<0.01,{ }^{\mathrm{c}} p<0.005,{ }^{\mathrm{d}} p<0.001$ compared with untreated diabetic rats

Table 2. Volume percentage of myocardial tissue components and myocytic structures

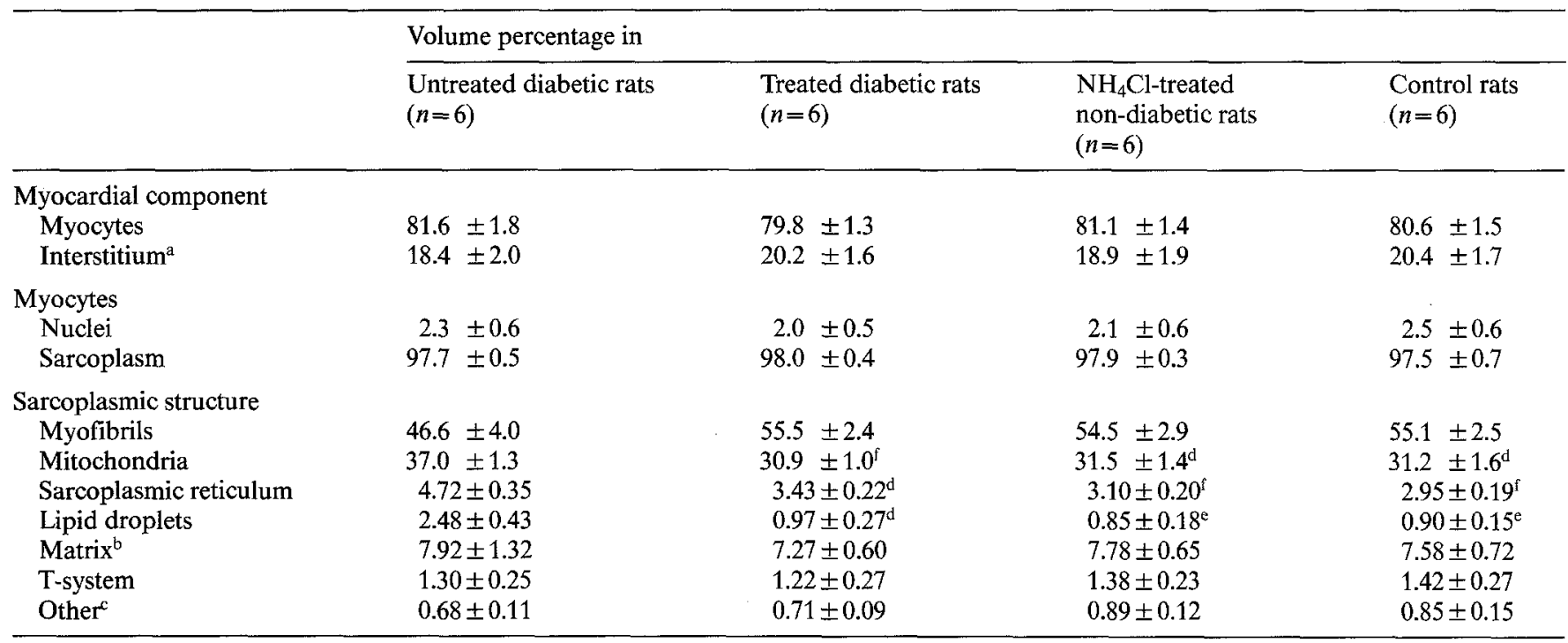

Results expressed as mean \pm SEM.

${ }^{a}$ Contains amorphous regions, fibres, capillaries and cells other than myocytes; ${ }^{b}$ includes glycogen, ribosomes, polyribosomes and amorphous regions; ${ }^{\mathrm{C}}$ includes rough endoplasmic reticulum, Golgi apparatus, peroxisomes and lysosomes; ${ }^{\mathrm{d}} p<0.02,{ }^{\mathrm{e}} p<0.01,{ }^{\mathrm{f}} p<0.005$ compared with untreated diabetic rats

Table 3. Number and area of the profiles of mitochondria and sarcoplasmic reticulum, and profile axes of mitochondria in the cardiac myocytes

\begin{tabular}{|c|c|c|c|c|}
\hline & $\begin{array}{l}\text { 7-day } \\
\text { untreated diabetic rats } \\
(n=6)\end{array}$ & $\begin{array}{l}\text { Treated diabetic rats } \\
(n=6)\end{array}$ & $\begin{array}{l}\mathrm{NH}_{4} \mathrm{Cl} \text {-treated } \\
\text { non-diabetic rats } \\
(n=6)\end{array}$ & $\begin{array}{l}\text { Control rats } \\
(n=6)\end{array}$ \\
\hline $\begin{array}{l}\text { Area/profile }\left(\mu \mathrm{m}^{2}\right) \\
\text { Mitochondria } \\
\text { Sarcoplasmic reticulum }\end{array}$ & $\begin{array}{l}1.28 \pm 0.09 \\
0.19 \pm 0.02\end{array}$ & $\begin{array}{l}0.83 \pm 0.07^{\mathrm{f}} \\
0.14 \pm 0.02\end{array}$ & $\begin{array}{l}0.78 \pm 0.09^{f} \\
0.10 \pm 0.03^{\mathrm{c}}\end{array}$ & $\begin{array}{l}0.70 \pm 0.08^{\mathrm{g}} \\
0.12 \pm 0.01^{\mathrm{e}}\end{array}$ \\
\hline $\begin{array}{l}\text { Profile axis/mitochondrio } \\
\text { Longitudinal }^{a} \\
\text { Transverse }^{\mathrm{b}}\end{array}$ & $\begin{array}{l}1.08 \pm 0.18 \\
0.91 \pm 0.10\end{array}$ & $\begin{array}{l}1.11 \pm 0.13 \\
0.72 \pm 0.11\end{array}$ & $\begin{array}{l}1.15 \pm 0.12 \\
0.61 \pm 0.06^{\mathrm{c}}\end{array}$ & $\begin{array}{ll}1.19 \pm 0.16 \\
0.62 \pm 0.05^{\mathrm{d}}\end{array}$ \\
\hline
\end{tabular}

Results expressed as mean $\pm \mathrm{SEM}$.

${ }^{a}$ Parallel to myofibrils; ${ }^{\mathrm{b}}$ Perpendicular to myofibrils; ${ }^{\mathrm{c}} p<0.05,{ }^{\mathrm{d}} p<0.025,{ }^{\mathrm{e}} p<0.01,{ }^{\mathrm{f}} p<0.005,{ }^{\mathrm{g}} p<0.001$ compared with untreated diabetic rats

myocytes was similar in the various groups (Table 3), but further measurements showed that the areas of the individual profiles of mitochondria and sarcoplasmic reticulum were greater in the untreated diabetic group than in $\mathrm{NH}_{4} \mathrm{Cl}$-treated and the control groups, and they were reduced in the former to normal level with insulin treatment (Table 3). Furthermore, the transverse axis of individual mitochondria was significantly greater in the 
untreated diabetic group than in the $\mathrm{NH}_{4} \mathrm{Cl}$-treated non-diabetic and in the control groups, but no significant differences were found in the length of the longitudinal axis of mitochondria between the various groups (Table 3).

\section{Observations of cardiac myocytes}

Lipid was accumulated in the cardiac myocytes of untreated diabetic animals as electron-opaque homogenous droplets, which were closely associated with the mitochondria (Fig.1A). No electron microscopically visible changes were found in the outer or inner mitochondrial membrane but the cristae were distorted (Fig. 1A). A regular finding in the untreated diabetic animals was the dilatation of the tubules of sarcoplasmic reticulum (Fig.1A). The mitochondrial matrix was more electron-lucent in the untreated diabetic animals (Fig. 1A) than in the insulin-treated diabetic (Fig. 1 B), $\mathrm{NH}_{4} \mathrm{Cl}$-treated non-diabetic (Fig. $1 \mathrm{C}$ ), and in the control animals (Fig. 1D), and patchy swelling was present in places (Fig. 1 A).

\section{Correlation of plasma parameters with the size of mitochondria}

In the diabetic untreated rats there was a positive correlation between the mean surface area of mitochondria and plasma NEFA concentration $(r=0.83, p<0.01)$. Similarly, in the untreated diabetic animals a positive correlation was found between the mean mitochondrial area and the concentrations of plasma acetoacetate $(r=0.87, p<0.005)$, and plasma $\beta$-hydroxybutyrate $(r=0.79, p<0.02)$, whereas no such correlations were found in the other groups.

\section{Discussion}

Of the mammalian tissues, the heart muscle uses the highest amount of energy $[14,15]$. In the normal fed state, glucose and NEFA are the main sources of energy in this tissue [16]. On the other hand, plasma ketone bodies become the main substrate for cardiac metabolism, when their blood concentrations rise, as in diabetes $[17,18]$. This study demonstrates ultrastructural alterations in the cardiac myocytes in short-term experimental diabetes, the state where both the concentrations of plasma NEFA and ketone bodies are increased.

A distinct finding in the untreated diabetic rats was the increase of the size of myocyte mitochondria. Even though no electron microscopically visible changes were found in the structure of outer or inner mitochondrial membranes, the matrix space was clearly swollen, and measurements of the longitudinal and transverse axes of mitochondria indicated that the mitochondria were taking a more rounded form in the untreated diabetic animals. Other findings were the dilatation of the tubules of sarcoplasmic reticulum and the accumulation of lipid in the cardiac myocytes of the untreated diabetic rats. Insulin treatment restored the size of mitochondria and of sarcoplasmic reticulum, and the amount of lipid in myocytes to the normal ranges, which suggests that the morphological changes found in the untreated diabetic animals were not due to the damaging effect of streptozotocin on the heart muscle, but that they were caused by the diabetic state per se. This suggestion is further supported by the finding that experimentally induced acidosis without diabetes did not cause any morphological alterations in the heart muscle. The blood haematocrit of the untreated diabetic animals was slightly higher $(0.41 \pm 0.02)$ than in $\mathrm{NH}_{4} \mathrm{Cl}$ treated non-diabetic $(0.37 \pm 0.02)$ and in control rats $(0.38 \pm 0.01)$. This rise does not explain the morphological changes found in these animals because the increase in blood haematocrit in untreated diabetic animals results from dehydration, i. e. from intracellular water loss [19], which, in fact should cause opposite morphological changes in cells, i.e. decrease of the size of cellular compartments.

The positive correlation between the size of mitochondria and plasma NEFA concentration suggests that there may be a relationship between the mitochondrial swelling and the level of plasma NEFA in shortterm untreated diabetic rats. Fatty acids are amphiphilic substances in that they contain both the hydrophilic (polar) and hydrophobic (non-polar) groups. The amphiphilic lipids can incorporate into biological membranes and change the physical properties of the lipid bilayer resulting in changes in the membrane function [20]. High fatty acid concentrations, by their detergentlike actions can abolish the ability of the membrane to serve as permeability barrier [20,21]. Even though most studies on the interaction between amphiphilic lipids and cellular membranes have been carried out using in vitro models [20-22], our findings could support the view that fatty acids may have a similar detergent-like action on biological membranes also in vivo, resulting in changes (increase?) of the permeability $[20,21]$ and in alterations (inhibition?) of certain enzyme activities [23] of mitochondrial membranes, thereby leading to the swelling of mitochondria.

The reason(s) for the positive correlation between the size of mitochondria and the levels of plasma ketone bodies in the untreated diabetic rats in our study remains unclear at the present time. Recently, decreased D- $\beta$-hydroxybutyrate dehydrogenase activity has been shown in liver mitochondria from diabetic rats [24], but the authors did not find any relationship between the lowered enzyme activity and the altered lipid composition of diabetic mitochondrial membranes [24].

Thus far, little attention has been paid to the ultrastructure of sarcoplasmic reticulum in acute insulin deficiency. Our present finding, i.e. the dilatation of the tubules of sarcoplasmic reticulum in the cardiac myocytes of untreated diabetic rats, however, may be related to the functional defects of sarcoplasmic reticulum reported earlier in diabetic rat hearts [25] and could result 
from the altered (increased?) permeability of cellular membranes during insulin deficiency [26, 27]. Interestingly, the dilatation of the sarcoplasmic reticulum in the ischaemic rat heart [28] has been proposed also to be related to the interaction between fatty acids and membrane lipids [20].

Biochemical studies have shown the concentration of myocardial triglycerides to be increased in alloxan[29] and streptozotocin-diabetic ketoacidotic rats [30]. Lipid, obviously triglyceride $[29,30]$, also accumulated in the cardiac myocytes of untreated diabetic animals in the present study, and as a summary of findings by others [29-31] it might be stated that accumulation of lipids in the heart muscle of ketoacidotic diabetic rats may just be a consequence of the activity of carnitine acyl transferase limiting the transport of fatty acids into mitochondria.

The size of mitochondria and of tubules of sarcoplasmic reticulum, as well as the amount of lipid droplets in the cardiac myocytes of insulin-treated diabetic rats were significantly smaller compared with those of untreated diabetic animals and similar with those of control rats, indicating that the ultrastructural alterations of the diabetic heart muscle are preventable with insulin treatment in this animal model. In conclusion, our findings indicate that the intracellular morphological changes in the cardiac myocytes of short-term diabetic rats are due to the diabetic state per se and point to an important role of insulin in the maintenance of the metabolism in heart muscle.

Acknowledgements: Presented in part at the 18th Annual Meeting of the Scandinavian Society for the Study of Diabetes, 1-3 June, 1983, Kuopio, Finland.

\section{References}

1. Regan TJ, Ettinger PO, Khan MI, Jesrani MU, Lyons MM, Oldewurtel HA, Weber M (1974) Altered myocardial function and metabolism in chronic diabetes mellitus without ischemia in dogs. Circ Res 35: 222-237

2. Ahmed SS, Jaferi GA, Narang RM, Regan TJ (1975) Preclinical abnormality of left ventricular function in diabetes mellitus. Am Heart J 89: 153-158

3. Seneviratne BIB (1977) Diabetic cardiomyopathy: The preclinical phase. Br Med J 1: 1444-1446

4. Penpargkul S, Schaible T, Yipintsoi T, Scheuer J (1980) The effect of diabetes on performance and metabolism of rat hearts. Circ Res 47: 911-921

5. Rubler S, Dlugash J, Yuceoglu YZ, Kumral T, Branwood AW, Grishman A (1972) New type of cardiomyopathy associated with diabetic glomerulosclerosis. Am J Cardiol 30: 595-602

6. Hamby RI, Zoneraich S, Sherman L (1974) Diabetic cardiomyopathy. JAMA 229: 1749-1754

7. Wheeler T, Watkins PJ (1973) Cardiac denervation in diabetes. $\mathrm{Br}$ Med J IV: $584-586$

8. Gundersen HJG, Neubauer B (1977) A long-term diabetic autonomic nervous abnormality. Diabetologia 13:137-140

9. Tarach JS (1976) Histomorphological and ultrastructural studies of a rat myocardium in experimental conditions. $Z$ Mikrosk Anat Forsch Leipzig 90: 1145-1157

10. Squires EJ, Hall DE, Brosnan JT (1976) Arteriovenous differences for amino acids and lactate across kidneys of normal and acidotic rats. Biochem J 160: 125-128
11. Blanchette-Mackie EJ, Scow RO (1971) Sites of lipoprotein lipase activity in adipose tissue perfused with chylomicrons. Electron microscope cytochemical study. J Cell Biol 51: 1-25

12. Anversa P, Loud AV, Vitali-Mazza L (1976) Morphometry and autoradiography of early hypertrophic changes in the ventricular myocardium of adult rat. An electron microscopic study. Lab Invest $35: 475-483$

13. Weibel ER, Bolender RP (1973) Stereological techniques for electron microscopic morphometry. In: Hayat MA (ed) Principles and techniques of electron microscopy: biological applications, Vol 3. Van Nostrand Reinhold, New York, pp 237-297

14. Opie LH (1968) Metabolism of the heart in health and disease. Part I. Am Heart J 76: 685-698

15. Opie LH (1969) Metabolism of the heart in health and disease. Part II. Am Heart J 77: 100-122

16. Robinson AM, Williamson DH (1980) Physiological roles of ketone bodies as substrates and signals in mammalian tissues. Physiol Rev 60: 143-187

17. Ungar I, Gilbert M, Siegel A, Blain JM, Bing RJ (1955) Studies on myocardial metabolism. IV. Myocardial metabolism in diabetes. Am J Med 18: 385-396

18. Fenselau A (1981) Ketone body metabolism in normal and diabetic man. In: Brownlee M (ed) Handbook of diabetes mellitus, vol 3: intermediary metabolism and its regulation. Garland STPM Press, New York London, pp 143-208

19. Hays RM, Levine SD (1976) Pathophysiology of water metabolism. In: Brenner BM, Rector FC (eds) The kidney, vol 1. WB Saunders, Philadelphia London Toronto, pp 553-614

20. Katz AM, Messineo FC (1981) Lipid-membrane interactions and the pathogenesis of ischemic damage in the myocardium. Circ Res 48: $1-16$

21. Helenius A, Simons K (1975) Solubilization of membrane by detergents. Biochim Biophys Acta 415: 29-79

22. Raz A, Livne A (1973) Differential effects of lipids on the osmotic fragility of erythrocytes. Biochim Biophys Acta 311: 222-229

23. Shug AL, Shrago E (1973) A proposed mechanism for fatty acid effects on energy metabolism of the heart. J Lab Clin Med 81: 214-218

24. Churchill P, McIntyre JO, Vidal JC, Fleischer S (1983) Basis for decreased $\mathrm{D}$ - $\beta$-hydroxybutyrate dehydrogenase activity in liver mitochondria from diabetic rats. Arch Biochem Biophys 224: 659-670

25. Penpargkul S, Malhotra A, Fein F, Strobeck J, Sonnenblick E, Scheuer J (1979) Myocardial biochemical alterations in experimental diabetes in rats. Clin Res 27:441 (Abstract)

26. Jungas RL (1981) Action of insulin on enzymes. In: Brownlee M (ed) Handbook of diabetes mellitus, vol 2: islet cell function insulin action. Garland STPM Press, New York London, pp 151-195

27. Moore RD, Munford JW, Pillsworth TJ, Jr. (1983) Effects of streptozotocin and fasting on intracellular sodium and adenosine triphosphate in rat soleus muscle. J Physiol 338: 277-294

28. McCallister LP, Trapukidi S, Neely JR (1979) Morphometric observations on the effects of ischemia in the isolated perfused rat heart. J Mol Cell Cardiol 11: 619-630

29. Rizza RA, Crass MF, Shipp JC (1971) Effect of insulin treatment in vivo on heart glycerides and glycogen of alloxan-diabetic rats. Metabolism 20: 539-543

30. Murthy VK, Shipp JC (1977) Accumulation of myocardial triglycerides in ketotic diabetes. Evidence for increased biosynthesis. Diabetes 26: 222-229

31. McGarry JD, Foster DW (1980) Systemic carnitine deficiency. N Engl J Med 303: 1413-1415

Received: 7 December 1983

and in revised form: 2 July 1984

Dr. Alli Reinilä

Department of Pathology

University of Oulu

Kajaanintie 52 D

SF-90220 Oulu 22

Finland 